\title{
IDEAS \& A planning tool for design and location of vegetative INNOVATIONS buffers on watercourses in the Canadian prairies
}

\author{
Alan Stewart, Sharon Reedyk, Bill Franz, Kim Fomradas, Clint Hilliard, and Shannon Hall
}

$\mathbf{V}$ egetated agricultural buffers are permanently vegetated areas that separate cropland from water bodies. At their simplest, buffers may be a strip of seeded forage separating field and stream, but they may also be more complex plantings of sequences of species, including grasses, forbs, shrubs, and trees. Natural vegetation can also serve as a buffer.

Buffers have many benefits. They act as filters for sediment and sediment-bound nutrients in runoff from cultivated fields. They provide a zone of infiltration for runoff in which dissolved nitrogen $(\mathrm{N})$ and phosphorus $(\mathrm{P})$ can enter the soil profile and subsequently be taken up by plants (Correll 1997). Buffers also provide a physical separation between agricultural activities, such as tillage and spraying, and water bodies (Wolf et al. 2005). Buffers are also effective habitat, both in themselves and as contributors to instream habitat conditions.

In Canada, establishment of buffer strips between cropped land and water bodies, particularly streams, is an accepted Best/ Beneficial Management Practice (BMP) and has been subsidized under incentive-based, environmental programming (AEFP 2007). In the prairie provinces of western Canada, buffers have been promoted primarily as a means of protecting water quality in a largely agricultural region with inherently eutrophic water bodies and high risk of $\mathrm{N}$ and $\mathrm{P}$ additions from cropping activities (AAFRD 2003). The contribution by buffers to wildlife

Alan Stewart is a senior soil specialist, Sharon Reedyk is a manager of Agricultural Water Quality Impacts, and Shannon Hall is a geographic information analyst at the Agriculture and AgriFood Canada, Agri-Environment Service Branch, Edmonton, Alberta, Canada. Bill Franz is a senior water quality specialist at the Agriculture and Agri-Food Canada, Agri-Environment Service Branch, Red Deer, Alberta, Canada. Kim Fomradas is a soil specialist and Clint Hilliard is a senior program analyst at the Agriculture and Agri-Food Canada, Agri-Environment Service Branch, Saskatoon, Saskatchewan, Canada. habitat and riparian health is also important in the region.

Vegetated buffers can be quite effective for removal of $\mathrm{N}$ and $\mathrm{P}$ from runoff water. Both these plant nutrients can be transported attached to eroding sediment or in dissolved forms. Sediment trapping ability of vegetated buffers has been related to several variables, and effectiveness has been shown to be proportional to particle size, buffer width, and sediment concentration and inversely proportional to flow rate and channel slope (Hayes and Dillaha 1992; Parsons et al. 1995; Robinson et al. 1996). There is conflicting evidence in the literature concerning the importance of the characteristics of the vegetation in a buffer. Generally, effectiveness increases with surface roughness, but mowed grass buffers have been documented as being more effective than natural vegetation in some experiments and less effective than natural forest in others (Parsons et al. 1994).

Dissolved plant nutrients can be removed by infiltration into the buffer zone. Percolating minerals may be taken up by plants and sequestered in plant tissue or escape in gaseous form. Most important of gaseous loss is in the form of nitrous oxides following microbial reduction of nitrate (Correll 1997). As with sediment removal studies, the research results from studies looking at dissolved nutrients vary widely. Most studies have reported some degree of effectiveness for nutrient removal (Parsons et al. 1995; Buffler 2005). Retention of $\mathrm{P}$ by the buffers has been found to be higher with mowing and removal of plant tissue (Uusi-Kamppa et al. 2000).

Much of the work on buffer efficacy has been conducted in controlled, plotscale experiments. Extrapolation of results to natural situations has largely been based on the assumption of sheet flow uniformly over the buffer area. Landscapes differ in three important ways. First, on actual landscapes there is a wide range of stream conditions and morphologies, and it is often difficult to determine where and how streams should be buffered. Second, streams are components of complex landscapes and there is a need to distinguish between segments of the landscape where buffers are an appropriate BMP and segments where they are not needed. Third, on most landscapes, runoff tends to become convergent flow as opposed to sheet flow. In general, the larger the field, the more flow is concentrated and the greater the importance of convergent flow. Recent reports identify concentrated flow as a factor affecting buffer effectiveness (Sheppard et al. 2006; Tomer et al. 2007; Dosskey et al. 2002), and others have indicated that modeling success for buffer effectiveness is greater when applied at or near a plot scale than when applied across a watershed as a whole in part because the models do not account for concentrated flows (Verstraeten et al. 2006). Finally, since cropped fields are the source of runoff, sediments, and nutrients there is a need to consider upland cropping practices as an element of buffer design.

This project was undertaken in response to the concerns identified by technical advisors responsible for providing advice about riparian buffer design. The goal was to develop a tool that provides a consistent approach to determining buffer needs and design in the prairie region. Technical staff pointed out many knowledge gaps from the perspective of practitioners in the Canadian Prairie region. Much of the research work used to develop buffer recommendations has been carried out in more temperate and humid environments, whereas the Canadian Prairies are a cold, subhumid to semiarid environment. The tool was designed to deal specifically with cropland settings, primarily for buffering streams from sediments and nutrients. A site-based approach was chosen as appropriate because each site is a unique blend of stream, landscape, and land management variables. The site based approach was also appropriate in the context of a voluntary conservation program, including technical support available to individual farm operations. It is assumed the interest in an assessment is identified by the landowner 
and that the landowner is actively engaged with the technical adviser in providing site information and discussing design options. The key design objectives of the tool are (1) to locate vegetated buffers where appropriate, (2) to determine the required shape of buffers, (3) to appropriately size buffers, and (4) to ensure that buffer design accommodates or complements upland management of the cropped land.

However, it was recognized that buffer size recommendations could at best be provisional because of the very limited work conducted on buffers in the region.

\section{BUFFER TOOL DEVELOPMENT}

The Canadian prairie agricultural region stretches across Manitoba, Saskatchewan, and Alberta. The region has a cold continental, subhumid to semiarid climate. Mean annual temperatures in the region range from about $2^{\circ} \mathrm{C}\left(35.6^{\circ} \mathrm{F}\right)$ to about $5.5^{\circ} \mathrm{C}\left(41.9^{\circ} \mathrm{F}\right)$. Monthly mean daily temperatures are below $0^{\circ} \mathrm{C}\left(32^{\circ} \mathrm{F}\right)$ from November to March, and soils are frozen for 3 to 5 months each year.

Precipitation in the prairie region ranges from about 300 to $550 \mathrm{~mm}(11.8$ to 21.7 in) annually. In general, about $70 \%$ to $80 \%$ of annual precipitation falls as rain in spring, summer, and fall. There is seldom overland runoff from rainfall. Winter precipitation is primarily snow, and wind typically redistributes a portion of the snow, concentrating it in sheltered areas of the landscape. Snowmelt usually takes place over about a one-month period in spring, with much of the melt taking place in a short, intensive melt period. As a result, snowmelt is the largest and most consistent annual runoff event in most areas of the prairie region.

Snowmelt takes place over cold, usually frozen ground. Frozen soils have lower infiltration rates than thawed soils, enhancing the runoff process. However, infiltration into frozen soil under permanent forage is higher than on cultivated soil (van der Kamp et al. 2003), and buffers can still be effective despite frozen soil conditions. In addition, soils usually have significant soil moisture storage potential as late-winter and early-spring soil moisture levels are usually well below field capacity.
Given the environment, we made the following assumptions in developing the tool:

1. The primary runoff occurs from spring snowmelt over frozen ground.

2. Trapping of soluble nutrients is primarily achieved through infiltration, and infiltration into a forage buffer is effective under prairie frozen soil conditions.

3. Sediment filtering by buffers is effective under frozen prairie conditions.

4. Nutrients are removed from the buffer zone through management (e.g., haying or appropriately timed and managed grazing).

To develop the approach, a variety of sites were evaluated on widely different landscapes in order to understand sitespecific processes in a landscape context. At each site, the focus was on describing the stream and stream conditions, the contributing watershed, the overland flow characteristics, and any other relevant conditions that might affect the site hydrology. Based on these observations it was determined what was considered necessary to buffer the stream by defining where buffers should be placed and how they should be fitted to the landscape. For example, sites were differentiated based on whether the overland flow from the slopes adjacent to the stream passed through the riparian zones as quasi-uniform sheet flow or in concentrated channels. Those sites with active floodplains and those susceptible to bank overflow flooding were differentiated from sites that had limited potential for bank overflow. Each of these scenarios required a different approach to buffer design.

An essential part of the fieldwork was identifying what parameters were used to make the recommendations, what indicators were used to assess the processes taking place on the landscape, and their importance relative to one another. These factors included, but were not limited to, signs of erosion, slope, aspect, microtopography, man-made changes to drainage (e.g., culverts), and upland conservation measures. These formed the basis for the generalizations that were then incorporated into a logic framework that could be used to assess any site. The logic framework used a keyed approach in which every step involved making YES or NO choices leading through to an end point. Finally, the logic framework was converted into standard key form with supporting definitions and descriptions to enable the user to interpret field conditions. The logic framework, key, and supportive information are available in a Field Manual on Buffer Design for the Canadian Prairies (Stewart et al. 2010), available from Departmental Publications Service at publications@agr.gc.ca.

After initial development, the logic framework and key were validated by undertaking a number of workshops with technical staff in various locations across the prairies. These were opportunities to test the system on a variety of landscapes and to get critical review by practitioners. The overall approach proved to be robust, and contributions from practitioners were incorporated in revisions to the decision support tool framework (figure 1).

\section{USING THE TOOL}

Prior to using the key, the investigator should review available information for the site and surrounding area. Topographic maps are important information sources about the watershed above the site, as well as near-site natural and anthropic controls of runoff.Aerial photos are also a source of landscape runoff indicators and may also provide information on land use. These resources can be used to build a picture of the site and surroundings that may influence the site hydrology. There may be other information sources that are available for the site, and investigators should seek them out as appropriate.

Topographic maps are valuable for delineating the stream watershed above the site. Upstream conditions control stream flows entering the investigation site and may be determinants of instream processes and impacts and flooding. In addition, topographic maps can reveal upstream conditions and features, for example dams, weirs, and other watershed modifications that may affect downstream hydrology.

Aerial photos are a valuable base for developing a visual understanding of the landscape, land use, and development at and around the site. Stereoscopic photos can be used to analyze terrain affecting 


\section{Figure 1}

Design tool logic framework.

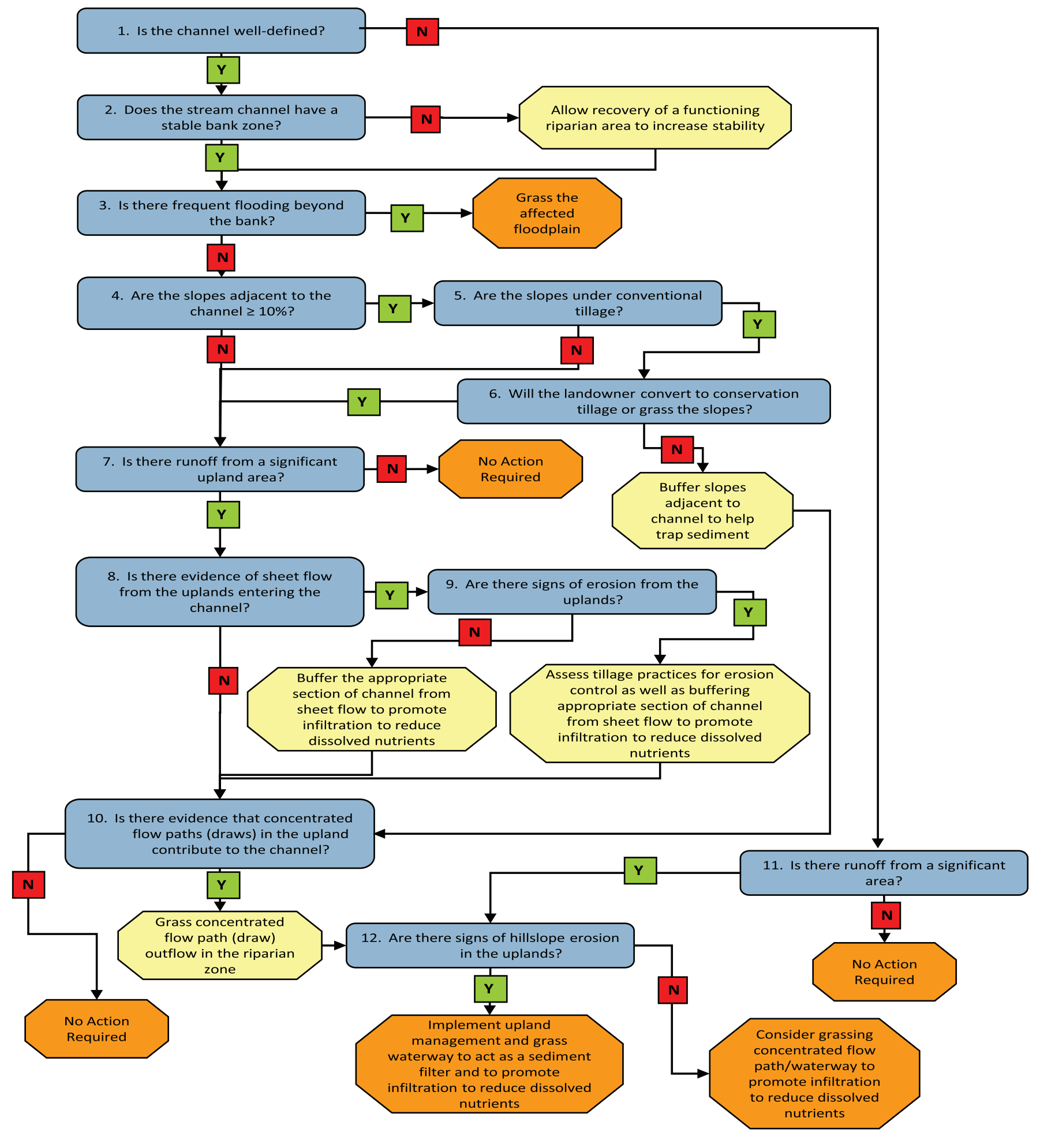

the site hydrology, especially the overland flow patterns and small catchments in or contributing to the site. Aerial photo interpretation is frequently needed in order to reinterpret regional information such as soils and geology at the site scale.

If possible, field inspections should be done with the landowner. The assump- tion is that the landowner instigates the investigation, and landowner interests and objectives are the ultimate basis of any actions that are taken. In addition to elab- 
orating on information already obtained, the landowner will have a much better knowledge of the specific parcel than the investigator and most likely a better appreciation of runoff patterns and amounts. Importantly, if the investigator's observations do not coincide with the landowner account, they can discuss the difference in order to get better understanding. Finally, investigators can get landowner information on farm practices both in the area immediately adjacent to the stream and in subwatersheds contributing runoff.

The key provides the steps for on-site investigation. On-site inspection involves walking the stream and identifying bank vegetation condition, bank failures shown by bare soil, seepage or springs, and sites where overland flows enter the stream. Bank failures need to be evaluated to determine their causes: failures caused by instream processes may need to be addressed by practices such as bioengineering rather than buffers, and failures resulting from overland flow or land management practices indicate a site that needs to be buffered, and the buffer itself may be an element of streambank restoration. The entire length of the stream on the property should be examined, and both sides of the stream should be considered. The key leads the investigation through evaluation of floodplains, if any, and the slopes immediately adjacent to the stream that may be direct sources of sediment and nutrients. It then addresses overland flow, identifying areas with negligible runoff, sheet runoff, or concentrated flow. Where there is runoff, the contributing subwatersheds need to be assessed by tracing the flows back up the landscape and mapping the subwatersheds in their entirety. Frequently there may be several subwatersheds with different runoff patterns on a property. As a rule the relative volumes of runoff are proportional to the subwatershed area, and it is important to identify local landscape depressions that may intercept and store overland flow, effectively limiting the amount that may reach the stream. Subwatersheds may extend beyond property boundaries, and off-property features affecting runoff need to be assessed. Roads, railways, ditches, other developments, and different land use or land manage- ment practices in subwatersheds can all affect site runoff even if they are not on the site itself.

Throughout the key, there are references to assessing or modifying upland management practices for conservation. In the prairie region, adopting reduced tillage production systems is the primary conservation practice. Users of the key should be aware that there are many production systems and cropping conditions, and the full gamut of conservation practices should be considered. Dryland small grain and oilseed production is the norm in the region and reduced tillage may be the first conservation choice, but users should consider all other relevant conservation options, especially where there are markedly different systems such as irrigated row crops.

An important condition for the key is that it requires YES or NO choices for conditions that on landscapes are really conditions of degree rather than conditions of class; thus, there is always an element of subjectivity or uncertainty. For this reason, training and experience in using the key are important. In addition, by identifying the choices that have a higher degree of uncertainty, users of the key can often identify conditions that can constructively be discussed with landowners.

\section{OUTCOMES}

The possible outcomes from application of the buffer tool are illustrated in the attached schematic (figure 2). A basic recommendation for all outcomes with well-defined channels is a minimal buffer made up of a permanently vegetated bank zone and an additional $3 \mathrm{~m}(9.8 \mathrm{ft})$ of nodisturbance zone. The first case illustrated is the basic recommendation applied where there is no frequent flooding and there is no significant overland runoff (figure 2a).

Where upstream watershed contributions are high enough to cause frequent flooding of the site, the recommendation is to seed the floodplain to permanent vegetation in addition to the basic protection of the bank and no-disturbance zone (figure $2 \mathrm{~b}$ ). In the prairie setting, the most likely common practice is seeding flood-tolerant forage in the floodplain. The buffer will minimize soil erosion and improve the opportunity for sedimentation of particulates in the floodwaters. Buffer forage management can use reduced fertilizer inputs and may have some benefit in reducing contributions the site may make to stream nutrient loading.

For floodplains that are above flood risk level, the basic bank and $3 \mathrm{~m}$ (9.8 $\mathrm{ft}$ ) no-disturbance zone is the minimum requirement (figure 2c). Any overland flow identified would require additional buffering.

Where overland sheet flow enters the stream channel, the length of stream affected by the sheet flow needs buffering (figure $2 \mathrm{~d}$ ). The dimensions of the buffer recommended will be determined by the purpose of the buffer, taking into consideration upland management practices that may affect the recommendation. For example, in a conventional tillage situation, a larger buffer would be recommended than for the same site under conservation tillage production. As a result, changes in upland management are an important factor in the recommendations to be considered.

Concentrated flow entering the channel needs to have the buffer placed at the confluence, shaping the buffer to fit the concentrated flow path and sizing the buffer to exceed the normal lateral extent of the runoff (figure 2e). There may be situations in which there is sheet flow adjacent to a concentrated flow path, in which case both should be buffered and the buffers merge with one another (figure $2 \mathrm{f}$ ).

Concentrated flow paths and channels that are not well defined are functionally the same. The basic recommendation to filter sediments and nutrients is to place the buffer in the channel in order to maximize sedimentation and infiltration (figure $2 \mathrm{~g})$. However, if there is significant sheet flow and erosion from the upland, the buffer may be extended beyond the channel in order to enhance sediment trapping (figure 2h). Again, the presence of erosion indicates a need to consider upland practice change.

Buffer sizing depends on the landscape settings and on objectives. The recommendations here are provisional, in part drawn from published work and in part empirical. The expectation is that the recommenda- 


\section{Figure 2}

Schematic of possible outcomes from application of the buffer tool.

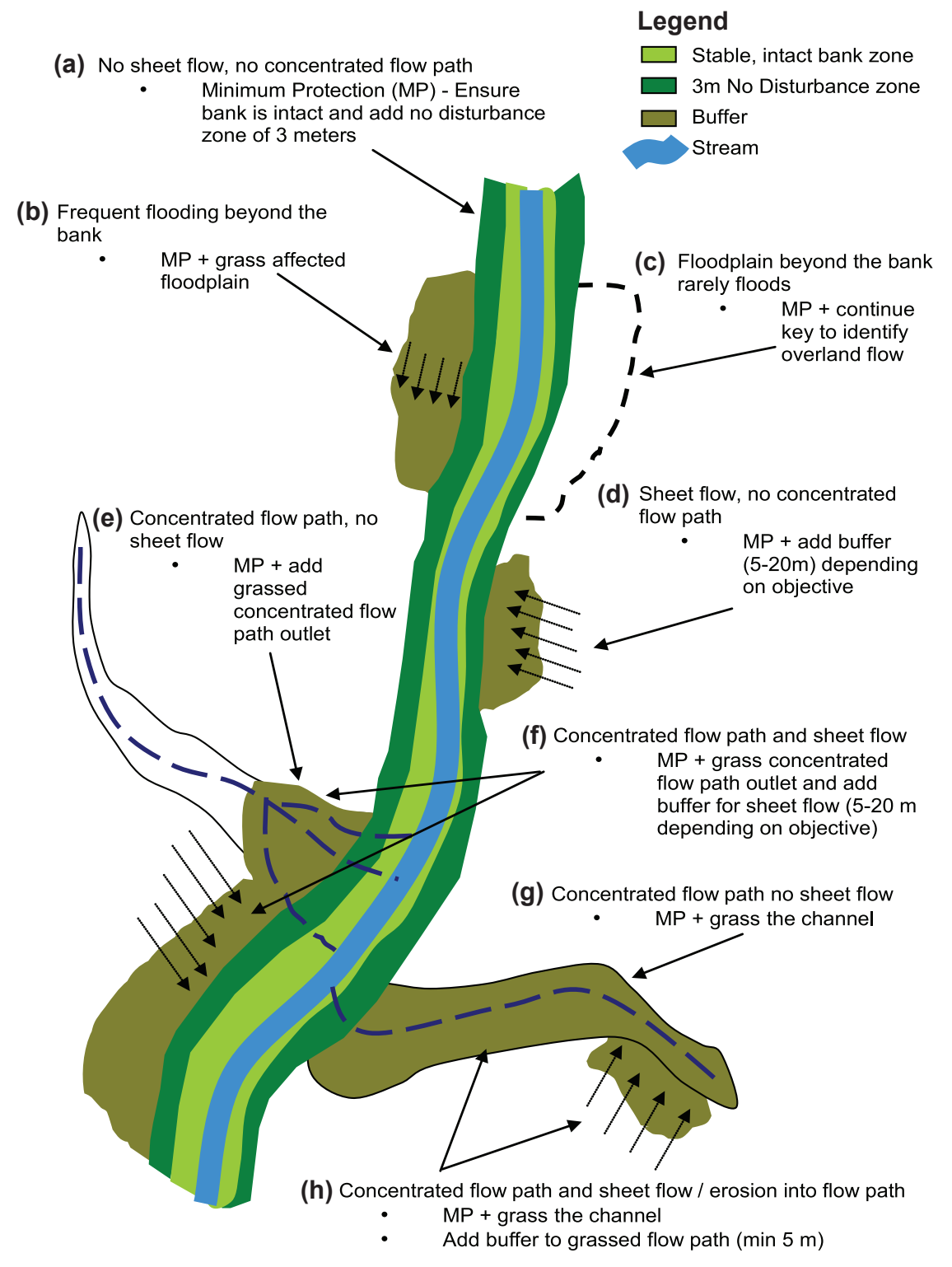

tions will be refined as information for the region is developed.

A basic recommendation is that all well-defined channel banks, defined by a distinctive, steeper slope, be protected by vegetation cover, and that an additional 3 $\mathrm{m}(9.8 \mathrm{ft})$ extending away from the top of the bank be retained as a no-disturbance zone. Ideally, bank vegetation cover is native to the area and is an undisturbed plant community typical of the area. In addition, ideally the no-disturbance zone is an extension of the bank. The objective of the bank and no-disturbance zone is to ensure bank integrity (Wynn 2006), particularly providing protection against instream erosion and farm implement impacts. The no-disturbance zone is also a minimal buffer for interception of sediment and nutrients (Dillaha 1989) and spray drift (Wolf et al. 2005).

Where there is a floodplain subject to frequent flooding, the entire floodplain is recommended to be put under permanent cover in addition to maintaining the basic bank and no-disturbance zone. Flooding is usually the result of upstream watershed conditions beyond the control of site landowners; therefore, the owners need to adapt to the flood risk. Permanent cover provides physical protection of the affected area and enhances the opportunity for sediment deposition from the floodwaters. In the prairie region, adapted flood-tolerant forages may be a preferred choice as they offer income opportunity through grazing or haying. Moderating fertilizer use in the floodplain may also limit soluble nutrient contributions to the creek. Spraying would not be a concern as it is not a normal forage production practice and there are potentially many variations that address wildlife objectives.

Buffers put in place to treat sheet flow need to extend along the creek for the whole extent of sheet flow into the creek. Most buffer sizing recommendations have been developed assuming sheet flow conditions. Although these studies may not be directly applicable to the prairie setting, we have used them to provide initial recommendations where the buffer tool identifies significant sheet runoff with the expectation that further work in the region will develop improved recommendations. Based on a summary of existing research, it is reasonable to recommend buffers as small as $5 \mathrm{~m}$ (16.4 ft) in addition to the bank zone to trap sediment (Dillaha et al. 1989; Magette et al. 1989) and provide protection from spray drift (Wolf et al. 2005). Increasing the size of the buffer to between 10 and $20 \mathrm{~m}$ (32.8 and $65.6 \mathrm{ft}$ ) targets removal of a greater percentage of sediment and soluble $\mathrm{P}$ and provides basic habitat protection for fish, birds, and small mammals (Abu-Zreig et al. 2003; Lee et al. 1999; Lee et al. 2003; Hawes and Smith 2005; Magette et al. 1989; Wenger 1999).

Buffers in concentrated flow paths are similar to grassed waterways for water erosion control. They are also effective protection against sediment loading and have been shown to reduce runoff volume and soluble nutrients (Fiener and Auerswald 2003). However, there are few sources for guidelines regarding sizing buffers for concentrated flows paths and channels that are not well defined. Establishing sizing guidelines is complicated as well by upland management practices which can be important in determining runoff volumes, sediment loading, and nutrient transport. 
In the absence of more detailed work we recommend that concentrated flow outlets to the main stream be buffered up the channel at least as far as any signs of sediment deposition or erosion of the flow path. The flow path should be examined along its full length for erosion and deposition, and the investigator may choose to recommend extending the buffer. In addition, consideration should be given to altering production practices in order to reduce flows. As these buffers tend to extend into fields, they have not generally been considered significant habitat.

In addition to considering concentrated flow pathways in designing buffers, it is worth remembering that many field margins adjacent to streams are irregular. Often it may be advantageous to squareoff fields in such a way as to extend the buffers beyond the minimum identified for flow path interception, while at the same time making the cropped field more regularly shaped and easier to work in with machinery. This approach is often more easily accommodated if the landowner is interested in grazing opportunities or has wildlife habitat interests.

Finally, extending the reasoning to making larger on-farm land-use adjustments is always worth considering. Landowners may find it advantageous to change the land use of an entire field rather than dividing the field into buffer and nonbuffer sections. In the final analysis, the most effective protection of waterways will be by securing vegetative cover that benefits the landowner in the context of the overall farm enterprise, and a basic land use adjustment, if considered, may provide that opportunity.

\section{CONCLUSIONS}

The decision support tool and key leads to identifying where buffers should be placed and how they should be fitted to the landscape, as well as alternate BMPs for the landscape. Outcomes from the key include situations with minimal overland runoff and minimal need for buffering, active floodplains, overland sheet flow and overland concentrated flow, as well as upland management changes. Buffer recommendations are suggested on an empirical assessment of site processes and, if available, from existing research.

There are opportunities to further develop the approach through the use of digital landscape analysis procedures and, where available, coupling local soil information with the landscape analysis. In addition to runoff definition, there may be opportunity to assess the partitioning of water by soils. Clearly, there are opportunities to improve and test guidelines for developing buffer size recommendations. The tool developed in this project incorporates design elements that reflect hydrological processes and agricultural practices specific to the Canadian Prairie region, but the approach developed here can likely be adapted for other environmental landscape and agricultural conditions by adjusting the indicators used in the key and assessment process.

\section{ACKNOWLEDGEMENTS}

Agriculture and Agri-Food Canada, AgriEnvironmental Services Branch support for this project is gratefully acknowledged. The authors thank Dr. David Chanasyk, University of Alberta, for his review of an earlier draft of the paper.

\section{REFERENCES}

AAFRD (Alberta Agriculture, Food and Rural Development). 2003. Buffer zones for a healthy watershed. http://www1.agric.gov. ab.ca/\$department/deptdocs.nsf/all/irr6419. Modified January 18, 2010.

Abu-Zreig, M., R.P. Rudra, H.R. Whiteley, M.N. Lalonde, and N.K. Kaushik. 2003. Phosphorus removal in vegetated filter strips. Journal of Environmental Quality 32:315-619.

AEFP (Alberta Environmental Farm Plan Company). 2007. Environmental Farm Plan, Version 2.1. The Alberta Environmental Farm Plan Company, 801, 4445 Calgary Trail, Edmonton, AB. T6H 5R7. www.AlbertaEFP.com.

Buffler, S. 2005. Synthesis of Design Guidelines and Experimental Data for Water Quality Function in Agricultural Landscapes in the Intermountain West. Appendix C, USDA National Agroforestry Center. http://www.unl. edu/nac/research/2005buffler.pdf.

Correll, D.L. 1997. Buffer zones and water quality protection: General principles. In Buffer Zones: Their Processes and Potential in Water Protection, eds. N.E. Haycock, T.P. Burton,
K.W.T. Goulding, and G. Pinay. Harpenden, UK: Quest Environmental.

Dillaha, T.A. 1989. Water quality impacts of vegetative filter strips. Paper No. 89-2043. St Joseph, MI: American Society of Agricultural Engineers 1499.

Dillaha,T.A., R.B. Reneau, S. Mostagnimi, and D. Lee. 1989. Vegetative filter strips for agricultural nonpoint source pollution control. Transactions of the American Society of Agricultural Engineers 32: 513-519.

Dosskey, M.G., M.J. Helmers, D.E. Eisenhauer, T.G. Franti, and K.D. Hoagland. Assessment of concentrated flow through riparian buffers. Abstract. 2002. Journal of Soil and Water Conservation 57(6):336-343.

Fiener, P. and K. Auerswald. 2003. Effectiveness of grassed waterways in reducing runoff and sediment delivery from agricultural watersheds. Journal of Environmental Quality 32: 927-936.

Hawes, E., and M. Smith. 2005. Riparian buffer zones: Functions and recommended widths. Report prepared for the Eightmile River Wild and Scenic Study Committee by Yale School of Forestry and Environmental Studies.

Hayes, J.C., and T.A. Dillaha. 1992. Vegetative filter strips: I. Site suitability and procedures, American Society of Agricultural Engineers paper \#922102. St. Joseph MI.

Lee, K.H., T.M. Isenhart, R.C. Schultz, and S.K. Michelson. 1999. Nutrient and sediment removal by switchgrass and cool-season grass filter strips in Central Iowa, USA. Agroforestry Systems 44:121-132.

Lee, K.H., T.M. Isenhart, and R.C. Schultz. 2003. Sediment and nutrient removal in an established multi-species riparian buffer. Journal of Soil and Water Conservation. 58(1):1-8.

Magette, W.L., R.B. Brinsfield, R.E. Palmer, and I.D. Wood. 1989. Nutrient and sediment removal by vegetated filter strips. Transactions of the American Society of Agricultural Engineers 32(2):663-667.

Parsons, J.E., J.W. Gilliam, R. Munoz-Carpena, R.B. Daniels, and T.A. Dillaha. 1994. Nutrient and sediment removal by grass and riparian buffers. In Environmentally Sound Agriculture: Proceedings of the 2nd Conference, American Society of Agricultural Engineers, April 20-22, 1994.

Parsons, J.E., J.W. Gilliam, T.A. Dillaha and R. Munoz-Carpena. 1995. Sediment and nutrient removal with vegetated and riparian buffers. In Clean Water - Clean Environment - 21st 
Century, Conference Proceedings, March 5-8, Kansas City, Missouri.

Robinson, M., M. Ghaffarzadeh, and R.M. Cruse. 1996. Vegetative filter strip effects on sediment concentration in cropland runoff. Journal of Soil and Water Conservation 50(3):227-230.

Sheppard, S.C., M.I. Sheppard, J. Long, B. Sanipelli, and J. Tait. 2006. Runoff phosphorus retention in vegetated field margins on flat landscapes. Canadian Journal of Soil Science. 86:871-884.

Stewart,A., S. Reedyk, B. Franz, K. Fomradas, C. Hilliard, and S. Hall. 2010. Field Manual on Buffer Design for the Canadian Prairies. Canada: AgriEnvironmental Services Branch, Agriculture and Agri-Food Canada.

Tomer, M.D, T.B. Moorman, J.L. Kovar, D.E. James, and M.R. Burkart. 2007. Spatial patterns of sediment and phosphorus in a riparian buf- fer in western Iowa. Journal of Soil and Water Conservation 62(5):329-338.

Uusi-Kamppa, J., B. Braskerud, H. Jansson, N. Syversen, and R. Uusitalo. 2000. Buffer zones and constructed wetlands as filters for agricultural phosphorus. Journal of Environmental Quality 29:151-158.

van der Kamp, G., M. Hayashi, and D. Gallen. 2003. Comparing the hydrology of grassed and cultivated catchments in the semi-arid Canadian prairies. Hydrological Processes 17:559-575.

Verstraeten, G., J. Poesen, K. Gillijns, and G. Govers. 2006. The use of riparian vegetated filter strips to reduce river sediment loads: an overestimated control measure? Hydrological Processes 20:4259-4267.

Wenger, S. 1999. A review of the scientific literature on riparian buffer width, extent and vegetation.
Office of Public Service Outreach. Institute of Ecology. University of Georgia. http:// outreach.ecology.uga.edu/tools/buffers/ lit_review.pdf

Wolf, T.M., A.J. Cessna, B.C. Caldwell, and J.L. Pederson. 2005. Riparian vegetation reduces spray drift deposition into water bodies. In Field Boundary Habitats: Implications for weed, insect and disease management, ed. A.G. Thomas. Topics in Canadian Weed Science 1:201-212. Sainte Anne de Bellevue, QC: Canadian Weed Science Society - Societe canadienne de malherbologie.

Wynn, T. 2006. Streambank Retreat: A Primer. Watershed Update 4(1). www.awra.org/ committees/techcom/watershed/pdfs/ 0401WU.pdf 